\title{
Concurrent myotomy and tunneling after establishment of a half tunnel instead of myotomy after establishment of a full tunnel: a more efficient method of peroral endoscopic myotomy
}

Authors

Institution
George M. Philips*, Sunil Dacha*, Steve A. Keilin, Field F. Willingham, Qiang Cai

Department of Medicine, Division of Digestive Diseases, Emory University School of Medicine, Atlanta, Georgia, USA submitted:

28. September 2015 accepted after revision:

5. January 2016

Dol http://dx.doi.org/

10.1055/s-0042-101787

Published online: 30.3.2016

Endoscopy International Open

2016; 04: E403-E408

(c) Georg Thieme Verlag KG

Stuttgart · New York

E-ISSN 2196-9736

Corresponding author

\section{Qiang Cai, MD, PhD}

Emory University School of Medicine

1365 Clifton Road, B1262

Atlanta, Georgia 30322

USA

Fax: +1-404-778-2578

qcai@emory.edu

\section{Bibliography}

Background and study aims: Peroral endoscopic myotomy (POEM) is a time-consuming and challenging procedure. Traditionally, the myotomy is done after the submucosal tunnel has been completed. Starting the myotomy earlier, after submucosal tunneling is half completed (concurrent myotomy and tunneling), may be more efficient. This study aims to assess if the method of concurrent myotomy and tunneling may decrease the procedural time and be efficacious.

Patients and methods: This is a retrospective case series of patients who underwent modified POEM (concurrent myotomy and tunneling) or traditional POEM at a tertiary care medical center. Modified POEM or traditional POEM was performed at the discretion of the endoscopist in patients presenting with achalasia. The total procedural duration, myotomy duration, myotomy length, and time per unit length of myotomy were recorded for both modified and traditional POEM.

\section{Introduction \\ $\nabla$}

Patients who have spastic esophageal motility disorders present with dysphagia, regurgitation, chest pain, and weight loss. Esophageal achalasia is the best defined of the spastic esophageal motility disorders and can be treated either endoscopically or surgically with disruption of the lower esophageal sphincter (LES) [1]. Traditional surgical disruption of the LES with laparoscopic Heller myotomy has been effective. Peroral endoscopic myotomy (POEM) is a conceptually similar but less invasive approach that does not require thoracoscopy or laparoscopy [2,3]. Since its advent in 2010 [2], worldwide adoption of the POEM procedure has progressed at a rapid rate.

\section{License terms}

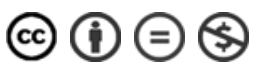

* These authors contributed equally to the study.
Results: Modified POEM was performed in 6 patients whose mean age ( \pm standard deviation [SD]) was $58 \pm 13.3$ years. Of these, 5 patients had type II achalasia and 1 patient had esophageal dysmotility. The mean Eckardt score $( \pm S D)$ before the procedure was $8.8 \pm 1$.3. The modified technique was performed in $47 \pm 8$ minutes, with $6 \pm 1$ minutes required per centimeter of myotomy and $3 \pm 1$ minutes required per centimeter of submucosal space. The Eckardt score was $3 \pm 1.1$ at 1 month and $3 \pm 2.5$ at 3 months. The procedure time for modified POEM was significantly shorter than that for traditional POEM.

Conclusions: Modified POEM with short submucosal tunneling may be more efficient than traditional POEM with long submucosal tunneling, and outcomes may be equivalent over short-term follow-up.Long-term data and randomized controlled studies are needed to compare the clinical efficacy of modified POEM with that of the traditional method.

POEM at times may be technically challenging and time-consuming; the reported POEM procedural times in most of the literature are longer than 1 hour [4]. A variety of modifications to improve the efficiency of the endoscopic approach have been developed [4-6], and these modifications of technique require additional tools and expense. Submucosal tunneling is an integral part of the POEM procedure. It usually takes a long time to establish a complete submucosal tunnel by dissecting submucosal fibers with endoscopic submucosal dissection knives.

To avoid perforation or mucosal injury during submucosal tunneling, accurate identification of the mucosal, submucosal, and muscularis layers is required. This is accomplished by creating a demarcation between the submucosal layer and the muscular layer with repeated injections of dyed saline (saline mixed with indigo carmine or methylene blue) during tunneling [7]. The process is 


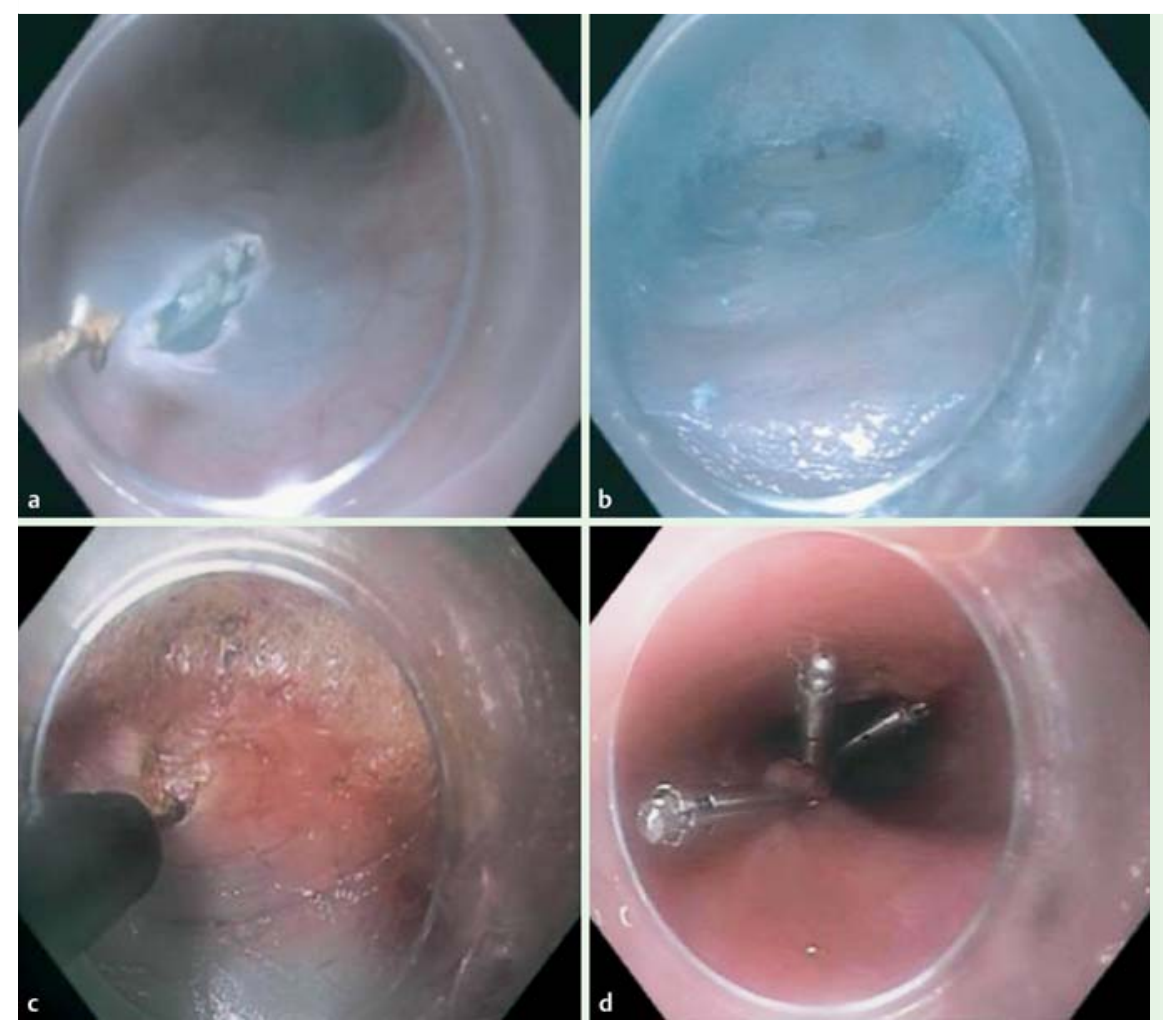

Fig. 1 The basic steps of endoscopic

myotomy. a Mucosectomy. b Submucosal tunneling. c Myotomy. d Closure.

time-consuming, and numerous exchanges of the injection needle and dissection knife are required during each POEM procedure [6]; therefore, the time spent on submucosal tunneling may account for most of the POEM procedural time. Reducing the time required to establish a long submucosal tunnel may be the best way to reduce the entire procedural time.

Traditionally, myotomy is performed after a submucosal tunnel approximately $12 \mathrm{~cm}$ long $(10 \mathrm{~cm}$ above and $2 \mathrm{~cm}$ below the gastroesophageal junction [GEJ]), is completely established. However, a completed submucosal tunnel may not be necessary for starting a myotomy. Most recently, a video case report of a similar modified technique in which submucosal tunneling and myotomy were performed concurrently suggested improved efficiency [8]. We hypothesized that starting a myotomy when the submucosal tunnel is half completed might significantly reduce the procedural time of POEM. To our knowledge, this is the first case series of concurrent myotomy and tunneling, termed modified POEM, whose results are presented here. We believe that this simple modification is inexpensive and flexible and that it improves the efficiency of the procedure by reducing the time necessary to establish a long submucosal tunnel.

\section{Methods \\ $\nabla$ \\ Patients}

Starting in December of 2013, all patients who were seen at our institution with an esophageal motility disorder, including achalasia, and were candidates for laparoscopic myotomy were offered POEM as part of a retrospective outcomes study approved by the institutional review board. Between November 2014 and March 2015, a modified POEM procedure was performed at the discretion of the endoscopist in six patients who opted to be treated with POEM.
Patient exclusion criteria included an inability to tolerate general anesthesia and prior endoscopic myotomy. Preoperative assessment included confirmation of a symptomatic esophageal motility disorder as defined by standard high resolution manometry, standard upper gastrointestinal endoscopy, barium swallow, and chest computed tomography. The data collected during the procedure included Eckardt score, length of myotomy, total duration of procedure, duration of submucosal tunneling, duration of myotomy, intraoperative and postoperative complications, and types and doses of anesthetic agents. The Eckardt score is a clinically accepted system for evaluating achalasia both before and after treatment [9]. Data derived included time per unit length of myotomy. Similar data were collected for six patients who underwent traditional POEM during the same period.

\section{Peroral endoscopic myotomy procedures}

Patient preparation and surgical technique have been described previously [10]. The same basic technique, proposed by others $[2,7]$, was used for all cases. All surgeries were performed in the endoscopy suite with the patient supine and under general anesthesia. Patients were given $4.5 \mathrm{~g}$ of piperacillin/tazobactam intravenously or $500 \mathrm{mg}$ of levofloxacin intravenously during the procedure. The esophagus was cleared of any retained particulate matter with lavage and suction. A submucosal wheal of normal saline dyed with methylene blue was created $10 \mathrm{~cm}$ above the endoscopically visualized GEJ in the posterior esophagus. An endoscope (GIF-H190; Olympus, Tokyo, Japan) with a transparent distal cap attachment (MH-588; Olympus) was used, and a 1.5 to 2-cm mucosectomy was created with a triangle tip knife (Olympus).

The technique consists of four basic steps: (i) mucosectomy, (ii) submucosal tunneling, (iii) myotomy, and (iv) mucosal resection closure [11] ( $\bullet$ Fig. 1). In the process of establishing a submucosal tunnel, repetitive cycles of dissection and injection with dyed normal saline are necessary to delineate the submucosal layer 

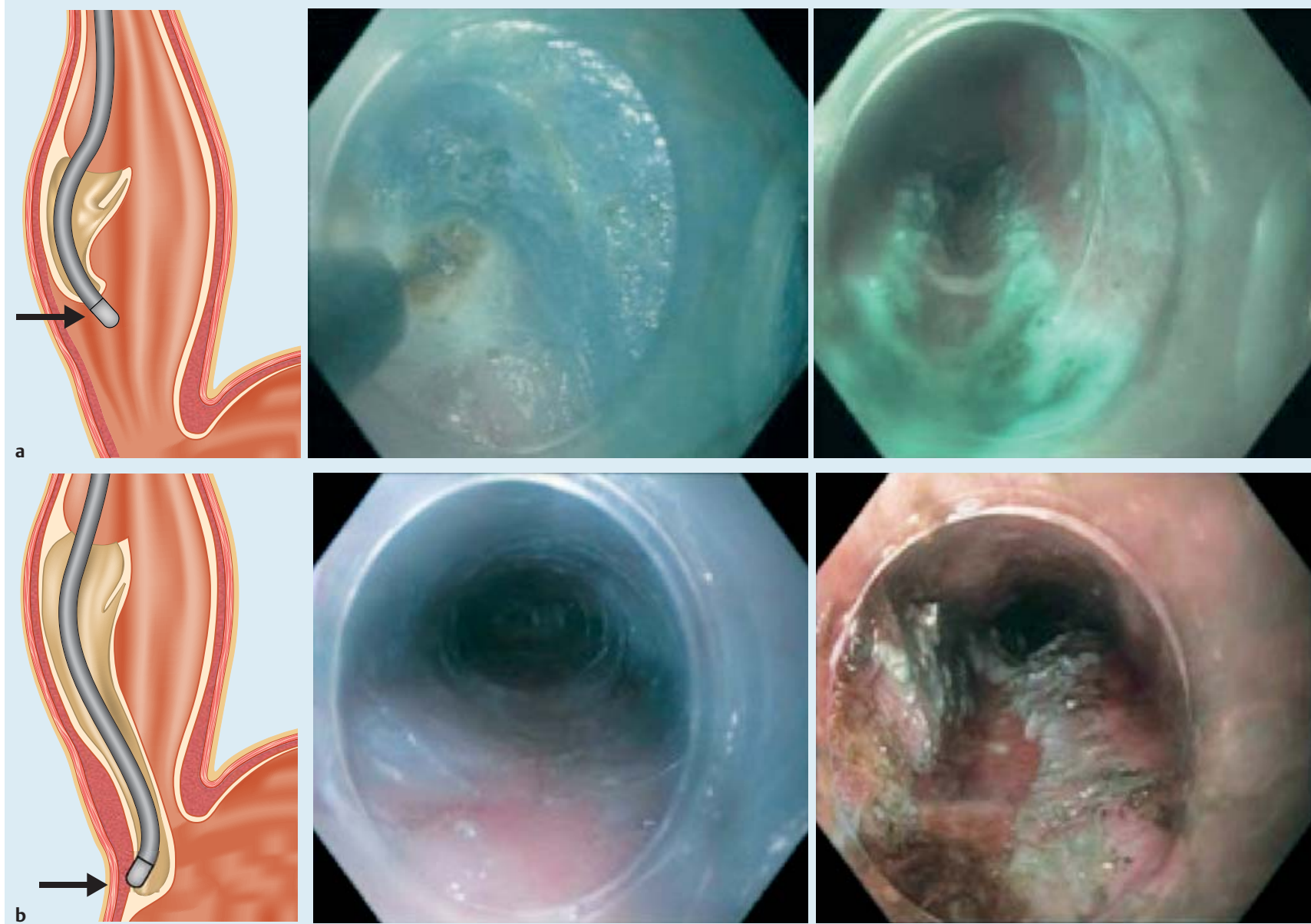

Fig. 2 a Modified approach. Submucosal tunneling and myotomy are performed concurrently. b Traditional approach. Submucosal tunneling is completed, and then a distal-to-proximal or proximal-to-distal myotomy is performed. The red arrows indicate initiation of the myotomy.

from the muscular layer and so avoid full-thickness perforation or mucosal injury. For traditional POEM, careful electrocauterization was used to extend a submucosal tunnel from $10 \mathrm{~cm}$ above the GEJ to approximately $2 \mathrm{~cm}$ past the GEJ into the gastric cardia. After a 12-cm tunnel had been completed, a distal-to-proximal or proximal-to-distal circular myotomy was performed ( $\bullet$ Fig. $2 \mathbf{b})$. For modified POEM, a proximal-to-distal circular myotomy was initiated after about half of the submucosal tunnel $(4-6 \mathrm{~cm}$ long) had been created and was then continued concurrently with extension of the submucosal tunnel ( $\bullet$ Fig. $2 a, \bullet$ Video 1 ). All procedures were performed by an attending physician experienced in POEM and an advanced endoscopy trainee. The attending physician had performed more than 50 POEM procedures before initiation of the study. Patients underwent modified or traditional POEM at the discretion of the endoscopist. The trainee's participation was fixed at 20 minutes per case, including 5 minutes for tunneling and 2 minutes for myotomy.

\section{Outcomes and follow-up}

The patients were admitted to the hospital after the procedure and followed in the clinic after discharge. At 1 and 3 months, their Eckardt scores were calculated. Immediate postoperative adverse events were recorded. Per protocol, all patients had a clinic visit at 1 month, and it was recommended that they undergo high resolution manometric analysis and a follow-up clinic visit at 3 months. In the entire cohort, 3 patients in the modified POEM group and 3 in the traditional POEM group returned for manometric evaluation.

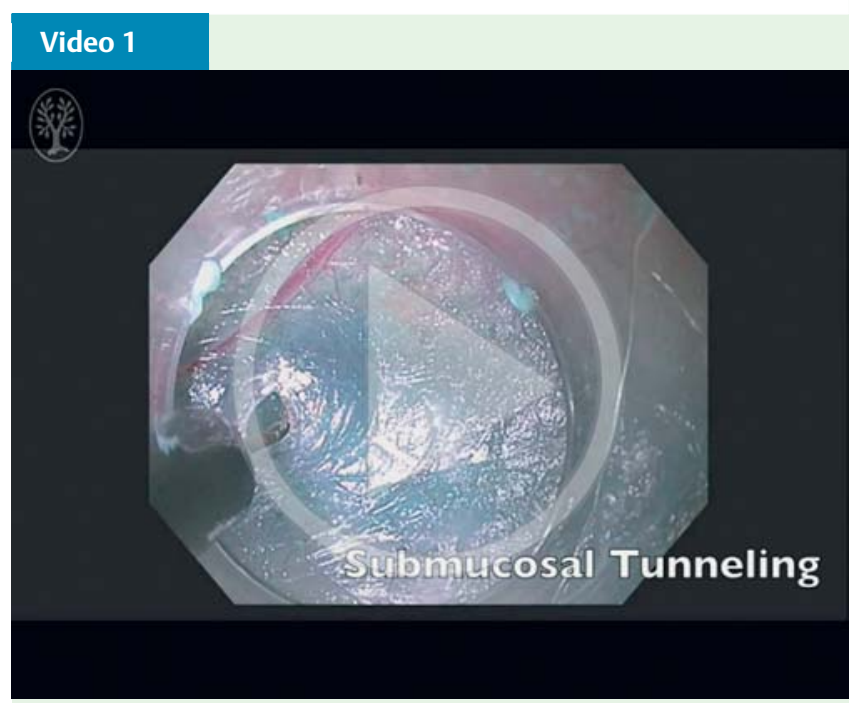

The modified peroral endoscopic myotomy procedure. Online content including video sequences viewable at: http://dx.doi.org/10.1055/s-0042101787 


\section{Statistics}

The paired Student's $t$ test was applied with Excel (Microsoft) to analyze the total length of the procedure, submucosal tunneling time, myotomy time, and submucosal endoscopic time (tunneling plus myotomy); the paired Student's $t$ test was also applied to compare the total time per unit length of myotomy and the submucosal endoscopic time per unit length of myotomy in the two groups. $P$ values of 0.05 or less were considered significant.

\section{Results}

$\nabla$

\section{Patient characteristics}

The modified POEM procedure, consisting of short tunneling followed by myotomy, was performed in 6 patients ( 1 male patient, 5 female patients; mean age $58 \pm 13.3$ years, range $42-66$; $\odot$ Table 1). Of these patients, 5 had a preoperative diagnosis of achalasia based on high resolution manometry; all had type II achalasia. In 1 patient, the manometric examination was not tolerated despite multiple attempts; achalasia was diagnosed based on expert opinion after clinical review and endoscopic, thoracic computed tomographic, and barium swallow examinations and was termed esophageal dysmotility ( $\bullet$ Table 2a). The baseline information for the patients who underwent traditional POEM is presented in $\bullet$ Table $2 \mathbf{b}$.

\section{Procedure times}

Total procedure time, tunneling time, and myotomy time The mean total procedure time was defined as the time elapsed from intubation of the esophagus to removal of the scope from the patient's mouth. The mean total procedure time $( \pm S D)$ was $47 \pm 8$ minutes for modified POEM and $67 \pm 13$ minutes for traditional POEM ( $\bullet$ Table 3$)$. Tunneling time was defined as the time elapsed from the initiation of tunneling to the completion of tunneling. Myotomy time was defined as the time elapsed from the initiation of myotomy to the completion of myotomy. The mean tunneling time $( \pm \mathrm{SD})$ was $10 \pm 4$ minutes for modified POEM and $27 \pm 7$ minutes for traditional POEM. The mean myotomy time $( \pm S D)$ was $16 \pm 8$ minutes for modified POEM and $8 \pm 2$ minutes for traditional POEM ( $\bullet$ Table 3$)$.

\section{Total time per centimeter of myotomy}

The total time per centimeter of myotomy was calculated as mean procedure time $(\mathrm{min}) /$ mean length of myotomy $(\mathrm{cm})$. The mean myotomy length $( \pm S D)$ was $7.5 \pm 0.8 \mathrm{~cm}$ for modified POEM and $6.8 \pm 0.4 \mathrm{~cm}$ for traditional POEM ( $\odot$ Table 3 ). When the time per unit length of myotomy was calculated, modified POEM required $6 \mathrm{~min} / \mathrm{cm}$ and traditional POEM required $10 \mathrm{~min} /$ $\mathrm{cm}$. This was calculated as follows: $47 \mathrm{~min} / 7.5 \mathrm{~cm}=6.3 \mathrm{~min} / \mathrm{cm}$ (modified POEM); $\quad 67 \mathrm{~min} / 6.8 \mathrm{~cm}=9.9 \mathrm{~min} / \mathrm{cm}$ (traditional POEM) ( $\odot$ Table3, $\odot$ Fig. 3a)

\section{Submucosal time per centimeter of myotomy}

Other factors, such as clearing the esophageal lumen, making the initial incision, and closing the incision, may affect the length of the procedure, and these factors are not associated with tunneling and myotomy. Therefore, we also calculated the submucosal time per centimeter of myotomy. The submucosal time (tunneling time plus myotomy time) was defined as time from the initiation of tunneling to the completion of myotomy. The mean tunneling time plus myotomy time $( \pm S D)$ was $26 \pm 8$ min for modified POEM and $36 \pm 8$ min for traditional POEM ( $\odot$ Table 3$)$. The
Table 1 Characteristics of the patients included in a study of modified and traditional peroral endoscopic myotomy (POEM).

\begin{tabular}{|c|c|c|}
\hline & $\begin{array}{l}\text { Modified POEM } \\
(n=6)\end{array}$ & $\begin{array}{l}\text { Traditional } \\
\text { POEM }(n=6)\end{array}$ \\
\hline Age, mean $\pm S D, y$ & $58 \pm 13.3$ & $53 \pm 19.7$ \\
\hline Gender (M:F) & $1: 5$ & $3: 3$ \\
\hline $\begin{array}{l}\text { Manometric diagnosis } \\
\text { (achalasia:dysmotility) }\end{array}$ & $5: 1$ & $5: 1$ \\
\hline
\end{tabular}

SD, standard deviation; M, male; F, female

Table 2 Characteristics of the patients included in a study of modified and traditional peroral endoscopic myotomy (POEM).

\begin{tabular}{|c|c|c|c|}
\hline Patient No. & Age, y & Manometric diagnosis & Eckardt score \\
\hline \multicolumn{4}{|c|}{ a Patients undergoing modified POEM } \\
\hline 1 & 63 & Type II achalasia & 10 \\
\hline 2 & 51 & Type II achalasia & 10 \\
\hline 3 & 47 & Type II achalasia & 12 \\
\hline 4 & 53 & Esophageal dysmotility & 12 \\
\hline 5 & 22 & Type II achalasia & 10 \\
\hline 6 & 82 & Type II achalasia & 9 \\
\hline \multicolumn{4}{|c|}{ b Patients undergoing traditional POEM } \\
\hline 1 & 66 & Type II achalasia & 8 \\
\hline 2 & 42 & Esophageal dysmotility & 10 \\
\hline 3 & 79 & Type II achalasia & 10 \\
\hline 4 & 60 & Type II achalasia & 7 \\
\hline 5 & 48 & Type II achalasia & 8 \\
\hline 6 & 53 & Type II achalasia & 10 \\
\hline
\end{tabular}

Table 3 Peroral endoscopic myotomy (POEM) procedural endpoints.

\begin{tabular}{|l|l|l|}
\hline & $\begin{array}{l}\text { Modified } \\
\text { POEM }\end{array}$ & $\begin{array}{l}\text { Traditional } \\
\text { POEM }\end{array}$ \\
\hline Total procedure time, mean \pm SD, min & $47 \pm 8$ & $67 \pm 13$ \\
\hline Myotomy length, mean \pm SD, cm & $7.5 \pm 0.8$ & $6.8 \pm 0.4$ \\
\hline Tunneling time, mean \pm SD, min & $10 \pm 4$ & $27 \pm 7$ \\
\hline Myotomy time, mean \pm SD, min & $16 \pm 8$ & $8 \pm 2$ \\
\hline $\begin{array}{l}\text { Tunneling time + myotomy time, } \\
\text { mean } \pm \text { SD, min }\end{array}$ & $26 \pm 8$ & $36 \pm 8$ \\
\hline
\end{tabular}

SD, standard deviation.

submucosal time per centimeter of myotomy was calculated as mean submucosal time $(\mathrm{min}) /$ mean length of myotomy $(\mathrm{cm})$, so that the following values were obtained: $27 \mathrm{~min} / 7.5 \mathrm{~cm}=3.6 \mathrm{~min} /$ $\mathrm{cm}$ (modified POEM); $37 \mathrm{~min} / 6.8 \mathrm{~cm}=5.4 \mathrm{~min} / \mathrm{cm}$ (traditional POEM). Therefore, modified POEM saved $1.8 \mathrm{~min} / \mathrm{cm}$ for myotomy and tunneling within the submucosal space $(\boldsymbol{G i g} . \mathbf{3 b})$.

\section{Sedative medication}

Only three anesthetic agents were consistently used across all the cases: fentanyl, propofol, and succinylcholine. The mean doses used for modified POEM and traditional POEM are listed - Table4. They were lower with modified POEM than with traditional POEM, although the difference was not statistically significant. Based on the time saved with modified POEM, we calculated the potential reduction in the cost of anesthetic agents. Again, because many factors may affect the total procedure time, we calculated the reduction in the amount of medication if the modified method was used in the patients who underwent traditional POEM. To calculate the potential savings for medication 


\begin{tabular}{|lll|}
\hline Anesthetic agent & Modified approach & Traditional approach \\
\hline Fentanyl, mean \pm SD, $\mu \mathrm{g}$ & $191.7 \pm 66.5$ & $237.5 \pm 77.1$ \\
\hline Propofol, mean \pm SD, $\mathrm{mg}$ & $255 \pm 104.3$ & $306.7 \pm 152.4$ \\
\hline Succinylcholine, mean \pm SD, mg & $75 \pm 62.5$ & $90 \pm 77.7$ \\
\hline Eckardt score, mean \pm SD & $8.8 \pm 1.3$ & $10.5 \pm 1.2$ \\
\hline
\end{tabular}

Table 4 Amounts of agents most commonly used for general anesthesia during the procedures.
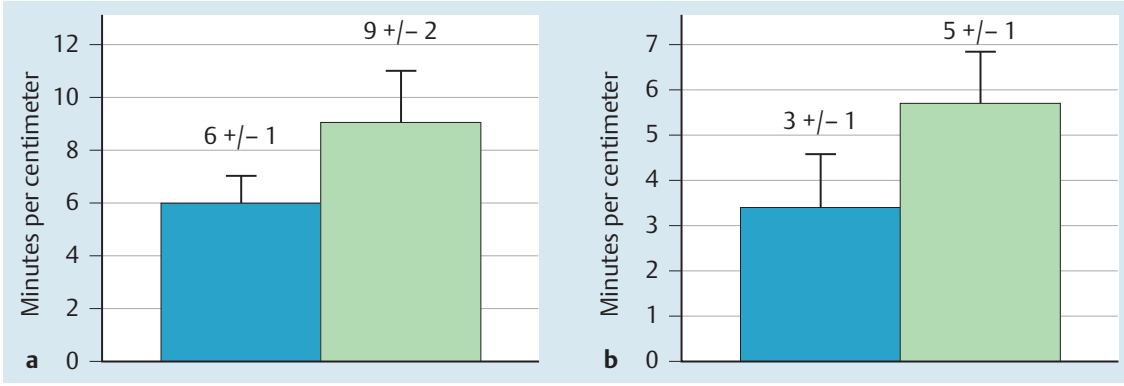

Fig. 3 a Total time per length of myotomy (minutes per centimeter). b Submucosal time per length of myotomy (minutes per centimeter). Black, modified myotomy; white, traditional myotomy.

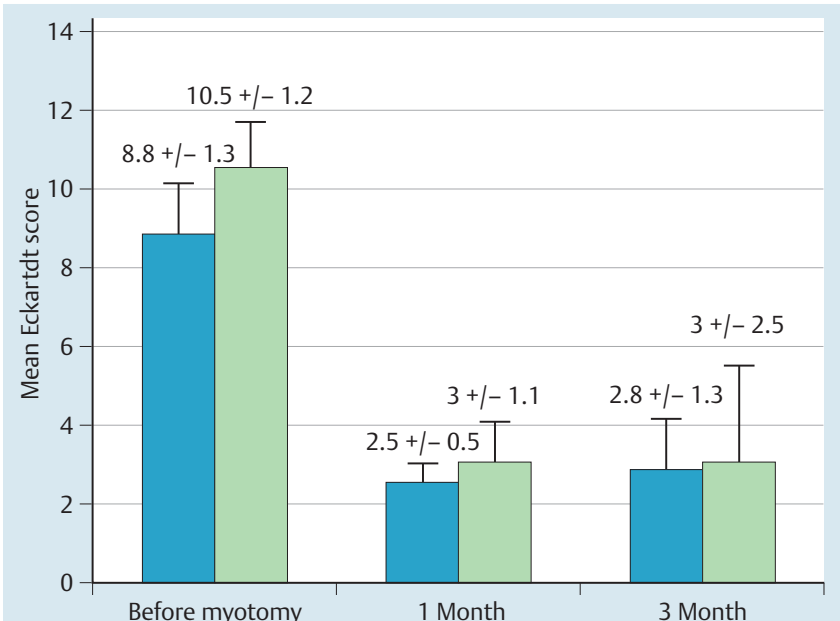

Fig. 4 Clinical outcomes at 1 and 3 months after modified (black) and traditional (white) peroral endoscopic myotomy.

(e.g., propofol) if we used the modified method in the patients who underwent traditional POEM, we first calculated the amount of propofol used during each minute of traditional POEM: $306 \mathrm{mg} / 67 \mathrm{~min}=4.5 \mathrm{mg} / \mathrm{min}$. With use of the modified method, we could save 1.8 minutes for each centimeter of myotomy; therefore, we could save 12.24 minutes for each patient who underwent traditional POEM $(1.8 \mathrm{~min} / \mathrm{cm} \times 6.8 \mathrm{~cm}=$ $12.24 \mathrm{~min}$ ). Then, we calculated the amount of medication that could be saved for each patient if we used the modified method in the patients who underwent traditional POEM $(12.24 \mathrm{~min} \times$ $4.5 \mathrm{mg} / \mathrm{min}=55.08 \mathrm{mg}$ ), with a saving of $\$ 330.48$ in 6 patients $(\bullet$ Table 5). Using the same method, we also calculated the savings for the other medications ( $\triangle$ Table5).

\section{Outcomes and complications}

One adverse event occurred in the modified POEM group, in which a patient developed thyrotoxicosis due to undiagnosed primary hyperthyroidism. No adverse events were reported in the traditional POEM group. All patients in both the modified POEM group and the traditional POEM group reported significant clinical improvement based on their Eckardt scores at 1 and 3 months after endoscopic myotomy ( $\bullet$ Fig.4). There were 3 pa-
Table 5 Potential anesthesia savings with change from traditional to modified peroral endoscopic myotomy (POEM).

\begin{tabular}{|c|c|c|}
\hline & $\begin{array}{l}\text { Average savings per } \\
\text { dose with modified } \\
\text { POEM }\end{array}$ & $\begin{array}{l}\text { Total savings with } \\
\text { six patients }\end{array}$ \\
\hline Fentanyl, $\mu \mathrm{g}$ & $\$ 43.40$ & $\$ 260.40$ \\
\hline Propofol, mg & $\$ 55.08$ & $\$ 330.48$ \\
\hline $\begin{array}{l}\text { Succinylcholine, } \\
\text { mg }\end{array}$ & $\$ 16.40$ & $\$ 98.40$ \\
\hline
\end{tabular}

Table 6 Manometric analysis of lower esophageal sphincter (LES) pressures before $(n=3)$ and after $(n=3)$ peroral endoscopic myotomy (POEM) for the two approaches.

\begin{tabular}{|lll|}
\hline Resting LES pressure & Modified POEM & Traditional POEM \\
\hline Before POEM, mean \pm SD, mmHg & $34.2 \pm 5.1$ & $34.6 \pm 16.3$ \\
\hline After POEM, mean \pm SD, $\mathrm{mmHg}$ & $13.5 \pm 1.9$ & $16.3 \pm 9.1$ \\
\hline
\end{tabular}

tients in the modified POEM group and 3 in the traditional POEM group who returned for manometric evaluation following myotomy ( $\bullet$ Table 6$)$.

\section{Discussion}

$\nabla$

As in laparoscopic surgical myotomy, an endoscopic submucosal tunnel is created in POEM to allow dissection of the inner circular muscles [2]. Potential complications are likely to be minimized as the overall duration of the procedure, exposure to anesthesia, and time within the submucosal space are decreased. A large portion of the procedure is devoted to establishing the submucosal tunnel; therefore, techniques to improve the efficiency of this step have emerged $[4,8,12,13]$. The current case series demonstrates a new, inexpensive modification of the current POEM technique that improves efficiency and may be used as an adjunctive measure combined with other modifications $[4,12]$ to expedite tunnel creation. To our knowledge, this is the first report of a series of patients undergoing modified POEM with concurrent tunneling and myotomy rather than traditional POEM with long tunneling before myotomy. 
In the patients treated with modified POEM, the procedure was safe, and they experienced good relief from the symptoms of achalasia as evidenced by improvement in their Eckardt scores and manometric parameters. The modified approach consists of the initial creation of a short submucosal tunnel, followed by myotomy, before the completion of submucosal tunneling; the benefit of the modified technique is directly related to the length of the myotomy. We observed a decrease in the submucosal time with the modified approach, and decreasing the total procedure time as well as the submucosal time may have important implications in reducing such adverse events as mediastinitis, submucosal infection, and symptomatic pneumoperitoneum. Furthermore, a reduction in the total procedure time may reduce the duration of exposure to anesthesia, thereby decreasing the complications of sedation and achieving secondary cost savings.

The adjustment in technique did not alter the clinical effectiveness of the procedure at 3 months. Clinical improvement, as measured by the Eckardt score, was similar in the modified and traditional approaches at 1 month and was sustained at 3 months after the procedure. Concurrently, the LES pressure after myotomy was significantly lower than the resting LES pressure before myotomy in both groups. This finding confirms that the modification in technique preserves the fundamental goal of reducing the LES pressure and relieving the clinical symptoms of achalasia. A posterior approach was used, as is practiced at our institution. Many practices may use an anterior myotomy or a myotomy in other locations during POEM. The feasibility of applying this modification with other approaches is unknown. The strength of modified POEM is its simplicity. The modified approach requires no additional resources and can be used as an adjunct to other techniques that improve efficiency. The myotomy was of the circular muscle fibers, not a full-thickness myotomy. This may also affect the safety and feasibility of the modified approach.

In this study, a triangle tip knife was used. This technique may be combined with other modifications (i.e., water jet-assisted dissecting knife or hybrid knife) to improve efficiency further $[4,6$, 12]. There are limited data suggesting that the use of a hybrid knife in expert hands, with the capability of injection and dissection, can save time during POEM by decreasing the frequency of accessory exchange; this needs to be confirmed in further studies, which will provide more answers on the benefits of the hybrid knife with modified POEM. In addition, the time saved per centimeter of myotomy (1.8 minutes) has important implications for POEM. As the technique has been extended to other types of spastic motility disorders, the myotomy lengths have also increased. Therefore, the modified approach may assist with further reductions in total time and submucosal time.

Considered as a whole, this case series demonstrates that the creation of a short, partial tunnel, followed by concurrent myot- omy and tunneling, significantly reduces total procedure time, total time per unit length of myotomy, and total time within the submucosal space. Liu et al. [8] briefly demonstrated the feasibility of the technique of simultaneous tunneling and myotomy in a video case report, but further study is required to evaluate the safety and efficacy of modified POEM. Our case series demonstrates not only its safety and feasibility but also improvements in short-term clinical outcomes. Randomized controlled studies in larger number of patients are also needed to demonstrate significant reductions in the administration of sedative medication and complications with the use of this modified approach to POEM, in addition to secondary cost savings.

\section{Competing interests: None}

\section{References}

1 Khashab MA, Saxena P, Kumbhari V et al. Peroral endoscopic myotomy as a platform for the treatment of spastic esophageal disorders refractory to medical therapy (with video). Gastrointest Endosc 2014; 79: $136-139$

2 Inoue H, Minami H, Kobayashi $Y$ et al. Peroral endoscopic myotomy (POEM) for esophageal achalasia. Endoscopy 2010; 42: 265-271

3 Pasricha PJ, Hawari R, Ahmed I et al. Submucosal endoscopic esophageal myotomy: a novel experimental approach for the treatment of achalasia. Endoscopy 2007; 39: $761-764$

4 Khashab MA, Messallam AA, Saxena $P$ et al. Jet injection of dyed saline facilitates efficient peroral endoscopic myotomy. Endoscopy 2014; 46: $298-301$

5 Cai MY, Zhou PH, Yao LQ et al. Peroral endoscopic myotomy for idiopathic achalasia: randomized comparison of water-jet assisted versus conventional dissection technique. Surg Endosc 2014; 28: 1158-1165

6 Zhou PH, Cai MY, Yao LQ et al. Peroral endoscopic myotomy for esophageal achalasia by HybridKnife: a case report. Case Rep Gastrointest Med 2012; 2012: 325479

7 Inoue $H$, Tianle KM, Ikeda $H$ et al. Peroral endoscopic myotomy for esophageal achalasia: technique, indication, and outcomes. Thorac Surg Clin 2011; 21: 519-525

8 Liu BR, Song JT, Omar Jan M. Video of the month. Modified peroral endoscopic myotomy. Am J Gastroenterol 2015; 110: 499

9 Eckardt AJ, Eckardt VF. Treatment and surveillance strategies in achalasia: an update. Nat Rev Gastroenterol Hepatol 2011; 8: 311-319

10 Swanstrom LL, Rieder E, Dunst CM. A stepwise approach and early clinical experience in peroral endoscopic myotomy for the treatment of achalasia and esophageal motility disorders. J Am Coll Surg 2011; 213: $751-756$

11 Khashab MA, Kumbhari V, Kalloo AN et al. Peroral endoscopic myotomy: a 4-step approach to a challenging procedure. Gastrointest Endosc 2014; 79: $997-998$

12 Khashab MA, Sharaiha RZ, Saxena P et al. Novel technique of auto-tunneling during peroral endoscopic myotomy (with video). Gastrointest Endosc 2013; 77: 119-122

13 Wang J, Tan N, Xiao Y et al. Safety and efficacy of the modified peroral endoscopic myotomy with shorter myotomy for achalasia patients: a prospective study. Dis Esophagus 2015: 28; $720-727$ 